\title{
Pra nem morta ser calada: arte afro- brasileira como fortalecimento identitário entre estudantes de medicina
}

\author{
Even in death, unsilenced: Afro-Brazilian art as identity fortification \\ instruments among medicine students
}

Marina Moreira $\mathbf{1}^{2}$

DOI: $10.1590 / 0103-1104202112915$

RESUMO Assolada pela violência e pela discriminação racial, a população negra integra os piores índices de vulnerabilidade à violência e indicadores de saúde. A Política Nacional de Saúde Integral da População Negra reconhece o racismo enquanto central na produção de iniquidades, mas não é capaz de superar a influência das teorias eugênicas no campo de saúde. Embora sejam parte expressiva dos profissionais da saúde, mulheres negras continuam encarando a inexpressiva produção de conhecimento sobre sua própria saúde. Questionando essa realidade excludente, este relato de experiência teve o objetivo de explorar a utilização da técnica de estêncil como instrumento de resistência para construção identitária e demarcação de território por alunas e alunos de medicina atingidos por processos de marginalização. Utilizando-se de materiais comuns ao cotidiano de profissionais de saúde, foi possível retratar diferentes imagens relevantes para a luta das minorias e para a identidade pessoal dos participantes. A partir da cultura negra, essa oficina atuou como centro de ensino e de mobilização social, possibilitando a criação de instrumentos de resistência e autoafirmação.

PALAVRAS-CHAVE Construção social da identidade étnica. Saúde das minorias étnicas. Arte.

\begin{abstract}
Plagued by violence and racial discrimination, the black population experiences the worst levels of vulnerability as to violence and health indicators. The National Policy for Comprehensive Health of the Black Population recognizes racism as central to the production of inequities, but is not able to overcome the influence of eugenic theories in the health field. Even though a significant part of health professionals, black women continue to face the inexpressive production of knowledge about their own health. Questioning this excluding reality, this experience report aims at exploring the use of the stencil technique as an instrument of resistance for identity construction and demarcation of territory by medical students affected by marginalization processes. Using materials common to the daily lives of health professionals, it was possible to portray different images that are relevant to the struggle of minorities and the personal identity of the participants. Based on the black culture, this workshop served as a center for teaching and social mobilization, enabling for the creation of both resistance and self-affirmation tools.
\end{abstract}

KEYWORDS Social construction of ethnic identity. Health of ethnic minorities. Art.

\footnotetext{
1 Universidade de Brasília (UnB) - Brasília (DF)

Brasil.

marinamoreira32@gmail.

com
} 


\section{Introdução}

O ‘Atlas da Violência de 2020' aponta para um Brasil dividido em dois países completamente distintos quando o tema é vulnerabilidade à violência'. A desigualdade racial se aprofundou na última década; e, entre 2008 e 2018, as taxas de homicídio aumentaram $11,5 \%$ para os negros, enquanto diminuíram 12,9\% para os não negros. No ano de $2018,75,7 \%$ das vítimas de violência letal foram negros e negras. Segundo o próprio anuário, na terra de Zumbi dos Palmares, o estado de Alagoas, a taxa de homicídios de negros supera em 17,2 vezes a de não negros, sendo o estado que apresenta maiores diferenças de vitimização entre negros e não negros' 1 .

Violência também é questão de saúde pública, e cada corpo negro caído no chão impacta direta e indiretamente a saúde física e mental da sua comunidade ${ }^{2}$. O medo afeta a forma como os negros se portam no mundo, sendo o racismo um fardo psicológico sobre pessoas negras ${ }^{2,3}$. Como já demonstrado por inúmeras pesquisas, o racismo expõe cotidianamente negros e negras a situações degradantes e humilhantes, tornando-os especialmente suscetíveis a desenvolver transtornos como taquicardia, hipertensão arterial, úlcera gástrica, ansiedade, ataques de pânico, depressão, dificuldade de se abrir, ataques de raiva violenta e aparentemente não provocada, comprometimento da identidade e distorção do autoconceito ${ }^{3}$.

Ao contrário do senso comum amplamente divulgado de tolerância e aceitabilidade do negro no Brasil, baseado no mito da democracia racial, temos que a discriminação racial tem efeitos diretos na saúde da população negra ${ }^{4}$, tornando-se, portanto, um problema de saúde pública. A Política Nacional de Saúde Integral da População Negra, aprovada em 2006 pelo Conselho Nacional de Saúde, e instituída em 2009 pelo Ministério de Saúde, reconheceu o racismo como central na produção de iniquidades em saúde, destacando sua forma institucional, dentro do próprio Sistema Único de Saúde 5 . Esse reconhecimento, apesar de importante no campo político, não foi capaz de superar a influência racista das teorias eugênicas no campo da saúde ${ }^{6}$.

Apesar de negados nos estudos atuais, não se deve esquecer o papel central que a medicina brasileira teve no fortalecimento de comportamentos discriminatórios e racistas ao abraçar os ideais eugenistas internacionais ${ }^{7}$. A divulgação desse conteúdo racista foi extensamente protagonizada por médicos brasileiros, por meio de atos como a criação da Sociedade Eugênica de São Paulo, em 1918, a realização do Congresso Brasileiro de Eugenia, a fundação da Liga Paulista de Higiene Mental e a publicação do periódico Boletim da Eugenia7. Segundo a produção desses influentes médicos do século XIX, que tinha caráter e status científico, ao nascer negro ou mestiço, a pessoa estaria determinada a uma maior propensão à loucura e a doenças por motivos biológicos, e não sociais ${ }^{8}$. Ao desqualificar as reais causas de adoecimentos e sofrimentos das pessoas negras e mestiças, associando-as a uma degeneração psíquica e social, a influência da história racista da medicina brasileira ultrapassou os consultórios e hospitais, passando a influenciar políticas públicas e sociais ${ }^{7}$.

Os efeitos históricos desse pensamento continuam a se manifestar nas diversas áreas de produção de conhecimento, favorecendo que a maior parte da produção científica brasileira permaneça alheia ao sofrimento de minorias étnicas ${ }^{2}$. Um exemplo claro é o caso das mulheres negras, que, ainda que sejam parte significativa dos profissionais da saúde e detentoras de vasta experiência histórica e cultural na arte de cuidar, seguem enfrentando a inexpressiva produção de conhecimento científico sobre sua própria saúde, que permanece um assunto vago, pouco abordado nos currículos de graduação e pós-graduação e ignorado pela maioria dos pesquisadores, estudantes, professores e profissionais de saúde no Brasile.

Instigados a questionar essa realidade excludente que permeia a academia e a clínica, e com o propósito de trazer diferentes olhares 
para a perspectiva formacional dos futuros profissionais de saúde, dois alunos do curso de graduação em medicina de uma universidade federal decidiram organizar uma oficina de estêncil para pintar as paredes brancas do centro acadêmico de estudantes com cores vivas e temática negra, retomando, por meio da arte, o espaço institucionalmente negado.

A oficina, realizada no dia 25 de setembro de 2018, foi aberta à comunidade acadêmica durante a semana universitária na Faculdade de Saúde e recebeu o nome 'Pra nem morto ser calado!, inspirado em uma música do rapper Djonga', de seu álbum 'Heresia', que tem como verso "largando linhas, pra nem morto ser calado". Dessa forma, este relato de experiência tem o objetivo de explorar a utilização da arte negra durante a oficina como instrumento para discussão de processos de construção identitária e demarcação do território por alunos e alunas atingidos por processos de marginalização.

\section{Material e métodos}

A pintura em estêncil é uma técnica popular do grafite que consiste na aplicação de tinta, em aerossol ou não, sobre molde geralmente feito de papel ou acetato. Os moldes utilizados na oficina foram elaborados pelos próprios participantes, a partir da reciclagem de chapas de raio-x cortadas com bisturis.

Inicialmente, foram escolhidas quatro imagens relevantes para a identidade pessoal dos participantes: o rosto de Marielle Franco (quatro camadas de tinta, quatro moldes); o símbolo do Partido dos Panteras Negras (quatro camadas de tinta, quatro moldes); o rosto de uma mulher negra em perfil com fundo do continente africano (camada e molde únicos); e um desenho gráfico acompanhado de um trocadilho questionando a heteronormatividade (camada e molde únicos).

As imagens passaram por tratamento de edição no computador (figura 1), conferindo-lhes camadas de cor que simulam a iluminação natural, de forma a alcançar o efeito desejado ao estêncil. A quantidade de camadas variou conforme a complexidade das imagens: apenas uma para as mais simples, e até quatro para as figuras mais complexas, como as de rostos humanos (figura 2).

Figura 1. Imagem do rosto de Marielle Franco após edição digital. O estêncil final terá quatro camadas de cor sobrepostas: preto, cinza, branco e preto

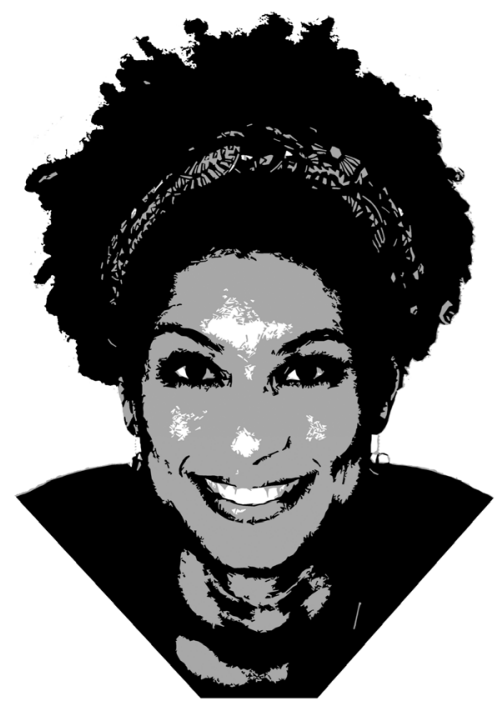


Figura 2. Foto das quatro chapas que correspondem a cada camada de cor do estêncil do rosto de Marielle Franco

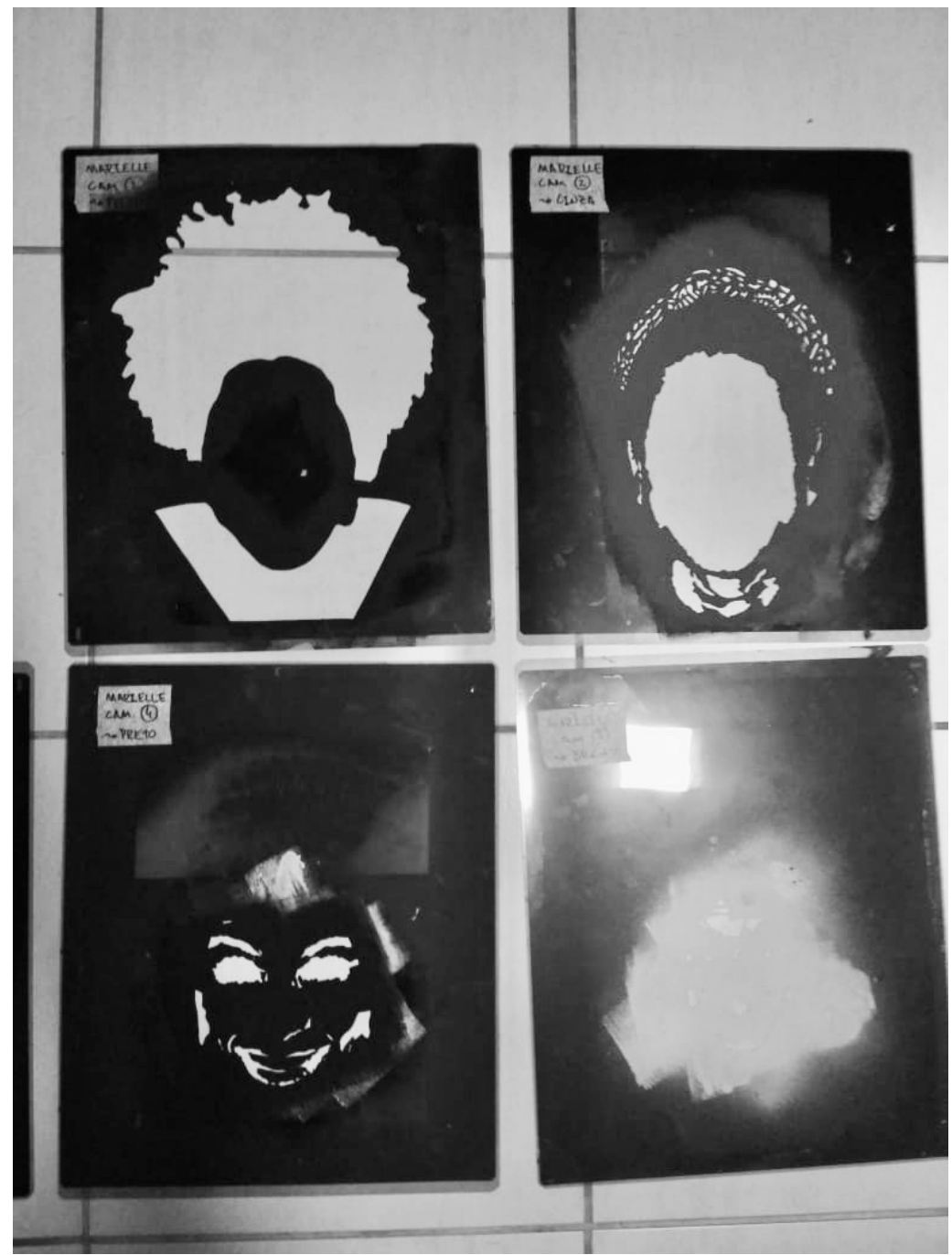

As camadas geradas foram então impressas em folhas brancas de papel de tamanho A3, utilizadas como moldes temporários para transferir as imagens para os moldes finais. Para tanto, foram sobrepostas às chapas de raio-x e cortadas em conjunto, com o uso de bisturis, seguindo os contornos e demarcações das folhas impressas. Nessa etapa, a mais demorada e delicada do processo, foram utilizadas mesas com tampo de vidro, de forma a aumentar o controle da superfície cortante e da pressão colocada sobre a folha.

Após o corte, as chapas de raio-x foram utilizadas como moldes para a aplicação de cada uma das camadas de tinta que, ao se combinarem, deram forma às imagens escolhidas para ocupar as paredes do centro acadêmico (figuras 3, 4 e 5). Durante toda a oficina, foram tocadas músicas de temática cultural negra, como o samba, o rap (sigla do inglês que significa ritmo e poesia), o funk e o hip-hop. 
Figura 3. Foto da arte final de estêncil aplicada na parede de símbolo do Partido Panteras Negras com a assinatura dos estudantes

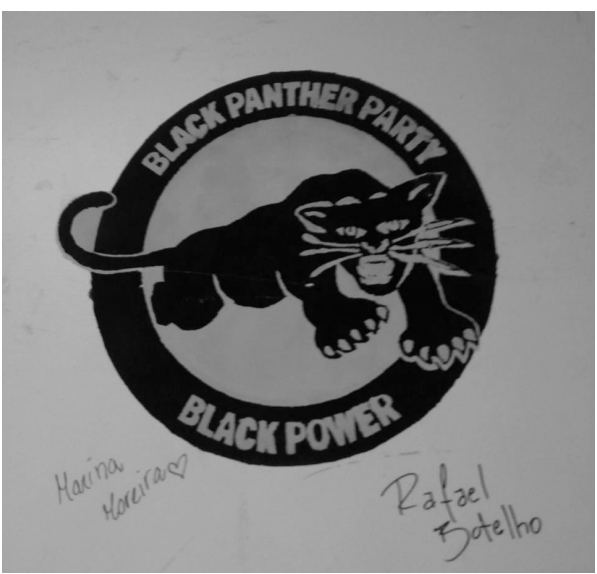

Figura 4. Foto da arte final de estêncil aplicada na parede do rosto de Marielle Franco com a assinatura da estudante depredada

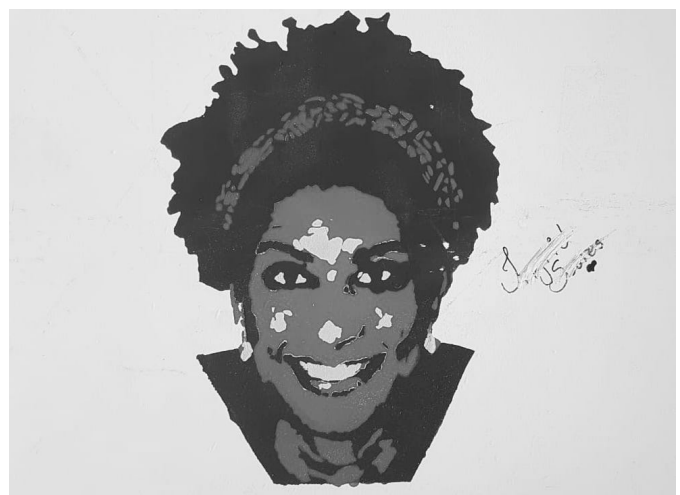

Figura 5. Foto da arte final de estêncil aplicada na parede de desenho gráfico rodeada de assinaturas de estudantes. Toda esta arte foi posteriormente depredada

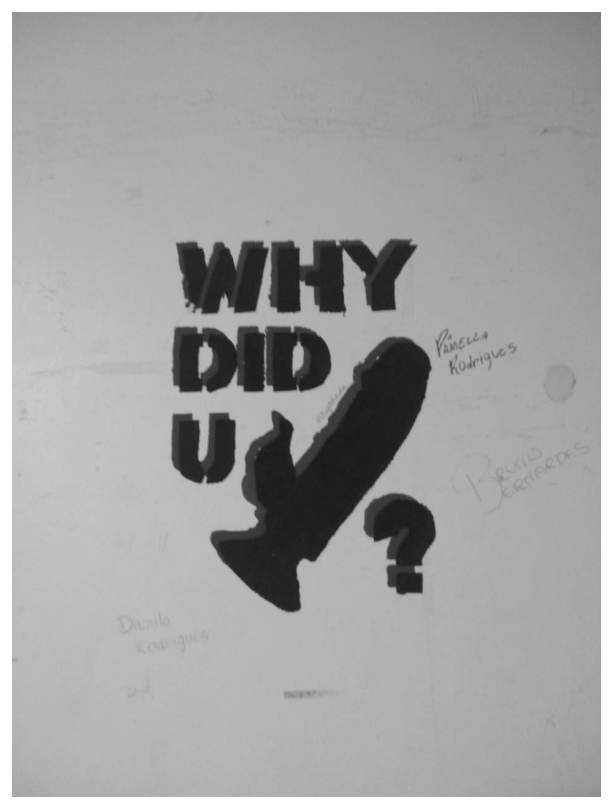




\section{A arte como resistência}

A escolha dos materiais - chapas recicladas de raio-x (cortesia do Hospital Universitário) e bisturis, utilizados no dia a dia de profissionais da saúde - não se deu ao acaso. Buscou-se reinventá-los e ressignificá-los, mostrando que é possível utilizá-los para fazer arte urbana e para retratar a cultura negra, como forma de resistência. Cultura, aqui, no sentido empregado por Stuart Hall, de guardar as tradições, mediante as quais as lutas sobrevivem na experiência histórica dos negros na diáspora, por meio da estética negra, dos repertórios culturais próprios e das contranarrativas que o povo negro luta para expressar ${ }^{10}$. A cultura urbana negra tem diversas manifestações que utilizam o espaço público como espaço de reunião, a exemplo do grafite, das danças e dos diversos estilos musicais. Dessa forma, para além do entretenimento e da arte, a música, uma das principais manifestações da cultura negra, apresenta-se como meio de construção de identidade e resistêncian", o que explica seu uso durante o processo de criação e aplicação das pinturas.

Assim sendo, as organizações de jovens em torno de movimentos artísticos étnicos (como o funk, o hip-hop e o rap) configuram instâncias educativas, já que os que participam delas o fazem em locais de educação política, com um espírito crítico e uma leitura mais criativa da realidade ${ }^{\mathbf{2}}$. São espaços que possibilitam a expressão da voz do marginalizado, bem como a reflexão sobre aquilo que exclui as classes menos favorecidas, sendo o rap especificamente o relato da violência, da exclusão, mas também da resistência e da riqueza cultural ${ }^{\mathbf{1}}$. Gustavo Pereira Marques, popularmente conhecido por seu nome artístico Djonga, é um dos maiores nomes do rap nacional' ${ }^{11}$. Nascido na favela do Índio em Belo Horizonte, foi aluno do curso de história da Universidade Federal de Ouro Preto e, atualmente, produz músicas que abordam o local social do negro, aprofundando-se em temas como racismo, violência policial, orgulho negro, tradições e ancestralidade, com evidente engajamento na construção da identidade e da resistência negra"1. Portanto, a escolha de seu verso para nomear a oficina evidencia o caráter de denúncia e esperança que esta compartilha com sua arte.

A educação política como projeto não é novidade para o movimento negro. Assumir a responsabilidade pela educação do seu povo tem sido uma constante na história das expressões africanas no Brasil; e como já evidenciado em vários projetos e práticas desse movimento, cultura e educação se relacionam intimamente ${ }^{\mathbf{1 2}}$. Infelizmente, os estudantes negros e cotistas sofrem, no espaço acadêmico, dupla discriminação: por serem cotistas e por serem negros, e o mero acesso à educação superior não tem sido garantia de uma identidade negra fortalecida ${ }^{\mathbf{1 3}}$. Ainda assim, é importante que esses estudantes se sintam parte desse novo espaço, para que se identifiquem com os demais universitários e com a cultura universitária ${ }^{13}$. Assim, a universidade pública federal, que vive uma mudança no perfil hegemonicamente branco dos acadêmicos desde a instauração das políticas de ações afirmativas ${ }^{13}$, tem a responsabilidade de fomentar eventos e oficinas de ressignificação cultural, física e emocional se quiser realmente construir um ensino integralizado e que dialogue com questões sociais. Somente possibilitar o acesso não é o suficiente.

O incômodo causado pela arte da oficina foi suficiente para levantar questionamentos e até mesmo depredações por outros do mesmo centro acadêmico. Dessa forma, ao participarem de eventos como essa oficina, os estudantes que se sentem marginalizados atuam como agentes políticos, e sua organização para a valorização da cultura afro-latina e do 'fazer arte negra' funciona não só como centro de ensino, mas também de mobilização social, tendo como epicentro as manifestações artísticas negras. Medidas educativas instrumentalizadas pela arte são ferramentas produtivas e intelectuais para a possibilidade de expressão pessoal e comunitária artística e 
emotiva. Desse modo, ao trabalharmos temas visuais culturais negros, estamos possibilitando a criação de instrumentos de resistência e autoafirmação em cada um.

Assim, a autoafirmação negra ganha o sentido de enaltecimento das características físicas fenotípicas (cabelo, nariz, boca e pele) e culturais estéticas (roupa, música e arte) permeando a revalorização de cada um desses traços, menosprezados historicamente $\mathrm{1}^{\mathbf{1 3}}$. Viver em um mundo de peles negras, máscaras brancas ${ }^{14}$, em especial em ambientes extremamente elitizados como o acadêmico, amplifica os efeitos de séculos de desvalorização pública e privada na autoestima de pessoas negras ${ }^{13}$. Logo, é necessário escolarizar-se também em maneiras de destruir os sentimentos de inferioridade dos traços corporais e culturais do negro, tanto em uma perspectiva acadêmica quanto social.

Para além disso, as vulnerabilidades em saúde são produtos da hierarquização social criadas por fatores estruturantes da sociedade, como o racismo e o sexismo ${ }^{6}$. No Brasil, essas vulnerabilidades foram acentuadas por séculos de práticas médicas eugênicas, como a esterilização involuntária ${ }^{7}$. As iniquidades são descritas em diversas pesquisas, sendo que mulheres negras apresentam menores chances de passar por consultas ginecológicas e de pré-natal completas, receber informações sobre o parto e seus sinais, sobre a alimentação saudável na gravidez e sobre o aleitamento materno e sua importância 4 . Em contrapartida, apresentam maiores chances de ter o primeiro filho com até 16 anos, de engravidar sem querer, de não receber assistência médica durante a gravidez e de não serem examinadas de forma correta ${ }^{4}$. Dados mais recentes apontam que, durante a pandemia mundial de Covid-19, populações de grupos étnicos minoritários foram desproporcionalmente afetadas ${ }^{15}$, sendo que, no Brasil, a mortalidade materna para mulheres negras em decorrência dessa infecção é quase duas vezes maior do que para mulheres brancas ${ }^{16}$.

Dessa forma, a escolha da figura da mulher negra, além de valorizar seus traços fenotípicos, possibilita trazer a discussão da invisibilidade das iniquidades que atingem essas mulheres. Deve-se recordar que as visões preconceituosas e estereotipadas de parcela dos profissionais de saúde colocam-se entre eles e os usuários pertencentes a grupos raciais marginalizados, abalando as relações de confiança interpessoais e entre os indivíduos e o sistema de saúde 6 . A falta de representatividade e discussão dessas iniquidades, na academia e na clínica, contribui para a manutenção da incapacidade dos profissionais de perceber as desigualdades de saúde, negando-as e colaborando para sua manutenção e ampliação ${ }^{4}$.

Racismo institucional, conceito cunhado por membros do Partido dos Panteras Negras, é um processo intrínseco do colonialismo que descreve a face sem rosto - mas ainda assim perversa e destrutiva - que opera a partir das forças respeitadas e estabelecidas na sociedade, evitando que serviços públicos, como a saúde, sejam ofertados na sua plenitude a pessoas por causa da sua cor, da sua cultura ou da sua origem étnica17. Provavelmente a dimensão mais ignorada do racismo, o racismo institucional é deslocado da dimensão interpessoal e praticado por indivíduos para a dimensão estrutural, valendo-se de ações e comportamentos de instituições públicas e privadas que produzem e reproduzem as hierarquias raciais, impregnando todo o sistema de saúde em todos os seus níveis e esferas ${ }^{6}$. Referência na luta antirracista, o símbolo do Partido dos Panteras Negras foi escolhido pelos participantes da oficina em reconhecimento ao extenso legado de produção cultural e acadêmica, representatividade, atos, legislações, histórias e esperança que o grupo representa para o povo negro em ascensão em todo o mundo.

Considerando-se o estêncil como ferramenta de resistência, ao pintarem as paredes do centro acadêmico com o rosto de Marielle Franco, os estudantes demarcaram território ideológico. Mãe, negra, mulher, bissexual e moradora da favela da Maré, Marielle Franco era vereadora da Câmara Municipal do Rio 
de Janeiro. No dia 14 de março de 2018, foi assassinada com quatro tiros na cabeça, em um atentado que atingiu o veículo em que ela e seu segurança se encontravam. Marielle havia acabado de participar de um debate intitulado 'Jovens negras movendo estruturas' na Casa das Pretas, com uma plateia cheia de negras universitárias ${ }^{\mathbf{1 8}}$. Favelada, aluna de pré-vestibular comunitário, formada por universidade pública e mestra em segurança pública, Marielle Franco dava voz aos excluídos também na academia ${ }^{19}$. Seu assassinato foi uma tentativa de calar uma das vozes de liderança política da comunidade negra. Uma bala que tenta calar a voz de resistência.

Lamentavelmente, o Brasil é líder mundial em assassinatos de transexuais e transgêneros, com mais que o triplo de homicídios do México, o segundo colocado ${ }^{20}$. No ano de 2019 , as vítimas contabilizadas em assassinatos de travestis e transsexuais no Brasil eram compostas em $82 \%$ por pessoas negras e em $97,7 \%$ por mulheres ${ }^{21}$. No que diz respeito ao acesso à saúde, a população de lésbicas, gays, bissexuais, travestis e transsexuais apresenta uma fragilidade peculiar, sendo muitas vezes vitimizada pela própria equipe de saúde ${ }^{\mathbf{2 2}}$. Medo de revelar sua identidade de gênero ou orientação sexual, estigma e discriminação (em especial relacionada com infecções sexualmente transmissíveis), desconhecimento médico quanto às variadas demandas de saúde, não uso do nome social, julgamento moral e religioso, reprovação pelas falas, gestos e olhares, desconhecimento da Política Nacional de Saúde Integral de Lésbicas, Gays, Bissexuais, Travestis e Transgêneros e transferência para os pacientes da culpa pelo tratamento de baixa qualidade são apenas alguns dos problemas observados na formação e atuação profissional médicas ${ }^{22}$. Isto posto, é urgente que se ampliem as discussões que questionam a heteronormatividade e a cisgeneridade compulsórias na formação em saúde, e que se atente especialmente para relatos e observações da vivência acadêmica de estudantes pertencentes aos grupos excluídos por essa norma. A escolha do desenho gráfico questionando a cis-heteronormatividade foi uma maneira bem-humorada encontrada pelos participantes da oficina de desafiar essa realidade violenta.

\section{Considerações finais}

Tantas são as mortes que vive o povo negro. $\mathrm{O}$ racismo, o medo e o silêncio como morte em vida. A indiferença, a difamação e o epistemicídio (apagamento dos conhecimentos construídos) ${ }^{23}$ como morte simbólica e espiritual. A negligência, a fome e o assassinato como morte física. Resistir, uma palavra que infiltrava cada atividade feita naquela oficina, tinha um significado que perpassava o valor cultural, a luta política e a autoestima de cada estudante que adentra um espaço elitizado, branco, heteronormativo, LGBTfóbico e racista, como o dos cursos superiores da área de saúde, em especial a medicina.

Hoje, na Faculdade de Saúde, ao se dirigir ao centro acadêmico de estudantes de medicina, é possível ver não somente o rosto de Marielle Franco, o rosto de uma mulher negra em perfil mesclado com o continente africano, o símbolo do Partido dos Panteras Negras e um desenho gráfico questionando a cis-heteronormatividade, mas também os nomes dos estudantes que assinam as obras, rodeando-as. As frias paredes brancas foram tomadas por nomes de pessoas negras e brancas, de diversidade amorosa, identitária e sexual como lésbicas, gays, bissexuais e travestis. Criou-se um espaço físico de autoafirmação que permanece para que todos os alunos possam admirar e dele participar.

Assinar os nomes com orgulho é demarcar um território que antes não somente era negado, mas ativamente produzia e, ainda que indiretamente, produz desconhecimento utilizado para colocar esses povos à margem da sociedade. Nessa oficina, utilizou-se do estêncil como forma de expressão da arte urbana, revestida de resistência. Os estudantes negros, cotistas, gays, lésbicas, bissexuais e travestis 
existem, resistem e ocupam a universidade pública, com seus corpos, suas vozes, sua pele, suas estéticas e seu conhecimento. De Martin Luther King a Marielle Franco, balas não calarão nossas vozes.

\section{Colaboradora}

Moreira M (0000-0002-3141-1932)* é responsável pela elaboração do manuscrito.

\section{Referências}

1. Instituto de Pesquisa Econômica Aplicada. Atlas da Violência 2020. 2020. [acesso em 2020 ago 29]. Disponível em: https://www.ipea.gov.br/atlasviolencia/ download/24/atlas-da-violencia-2020.

2. Gouveia DM, Loyola ZVM. Saúde Mental e Racismo Contra Negros: Produção Bibliográfica Brasileira dos Últimos Quinze Anos. Psicol Ciência e Profissão. 2018 [acesso em 2020 jul 29]; 38(3):450-64. Disponível em: https://doi.org/10.1590/1982-37030003262017.

3. Silva ML. Racismo e os Efeitos na Saúde Mental. In: Batista LE, Kalckmann S, organizadores. Seminário saúde da população negra Estado de São Paulo 2004. São Paulo: Instituto de Saúde; 2005. p. 129-132.

4. Lopes F. Experiências desiguais ao nascer, viver, adoecer e morrer: tópicos em saúde da população negra no Brasil. In: Batista LE, Kalckmann S, organizadores. Seminário saúde da população negra Estado de São Paulo 2004. São Paulo: Instituto de Saúde; 2005. p. 53-101.

5. Brasil. Ministério da Saúde, Secretaria de Gestão Estratégica e Participativa. Política Nacional de Saúde Integral da População Negra: uma política do SUS. 3. ed. Brasília, DF: Editora do Ministério da Saúde;
2017. [acesso em 2020 jul 29]. Disponível em: www. saude.gov.br/bvs.

6. Werneck J. Racismo institucional e saúde da população negra. Saude e Soc. 2016; 25(3):535-49.

7. Verzolla BLP, Mota A. Representações do discurso médico-eugênico sobre a descendência: a eugenia mendelista nas teses doutorais da faculdade de medicina e Cirurgia de São Paulo na década de 1920. Saude e Soc. 2017; 26(3):612-25.

8. Engel MG. As fronteiras da 'anormalidade': psiquiatria e controle social. Hist. Ciênc. Saúde-Manguinhos. 1999 [acesso em 2020 jul 31]; 5(3):547-63. Disponível em: http://www.scielo.br/scielo.php?script=sci arttext\&pid=S0104-59701999000100001\&lng=pt\&t lng=pt.

9. Djonga. Heresia [Youtube]. [2017]. [acesso em 2020 jul 29]. Disponível em: https://music.youtube.com/ playlist?list=OLAK5uy_lKyF7uVNh3nnAy5g2Xs8bknMJCpoC6WHI.

10. Hall S. Da Diáspora: Identidades e Mediações Culturais. Belo Horizonte: Editora UFMG; 2003.
*Orcid (Open Researcher and Contributor ID). 
11. Fernandes G, Azevedo N, Santos S, et al. O rap como ferramenta de resistência: A influência da musicalidade de Djonga para a construção de sentido da luta negra no País. In: Anais do $24^{\circ}$ Congresso de Ciências da Comunicação na Região Sudeste; 2019 Jun 3-5; Vitória. Vitória: UFES; 2019.

12. Gonçalves LAO, Silva PBG. Movimento negro e educação. Rev Bras Educ. 2000; (15):134-58.

13. Marques EPS, Ribeiro MAPS. O fortalecimento da identidade negra na educação superior: entre a negação e o reconhecimento. Interfaces da Educ. 2017; 8(23):53-73.

14. Fanon F. Pele negra, máscaras brancas. Salvador: EDUFBA; 2008.

15. Khunti K, Kumar Singh A, Pareek M, et al. Is ethnicity linked to incidence or outcomes of covid-19? BMJ. 2020 [acesso em 2020 jun 7]; 1-2. Disponível em: https://www.bmj.com/content/369/bmj.m1548.

16. Santos DS, Menezes MO, Andreucci CB, et al. Disproportionate impact of Coronavirus Disease 2019 (COVID-19) among pregnant and postpartum Black Women in Brazil through structural racism lens. Clin Infect Dis. 2020 [acesso em 2020 jul 29]; 72(11):20682069. Disponível em: https://academic.oup.com/cid/ article-abstract/doi/10.1093/cid/ciaa1066/5877027.

17. Carmichael S, Hamilton C. Black power: the politics of liberation in America. Vintage. Nova Iorque: Random House; 1992.
18. Mesquita L. Os últimos momentos de Marielle Franco antes de ser morta com quatro tiros na cabeça. BBC News Brasil. 2018 mar 15. [acesso em 2020 jul 31]. Disponível em: https://www.bbc.com/portuguese/ brasil-43414709.

19. Franco M. UPP - A redução da favela a três letras: uma análise da política de segurança pública do estado do Rio de Janeiro. [dissertação]. Niterói: Universidade Federal Fluminense; 2014.

20. Balzer C, Lagata C, Berredo L. 2,190 murders are only the tip of the iceberg-An introduction to the Trans Murder Monitoring project - TMM annual report 2016. Germany: TvT Publication; 2016. [acesso em 2020 jul 31]. Disponível em: www.tgeu.orgwww. transrespect.org.

21. Benevides BG, Nogueira SNB. Dossiê dos assassinatos e da violência contra travestis e transexuais brasileiras em 2019. São Paulo: Expressão Popular, ANTRA, IBTE; 2020.

22. Negreiros FRN, Ferreira BO, Freitas DN, et al. Saúde de Lésbicas, Gays, Bissexuais, Travestis e Transexuais: da formação médica à atuação profissional. Rev Bras Educ Med. 2019; (43):23-31.

23. Montenegro AMR. Resenha Carneiro S. Escritos de uma vida. São Paulo: Pólen Livros, 2019. Cad da Esc do Legis. 2019; 21(35):163-75.

Recebido em 31/08/2020

Aprovado em 05/03/2021

Conflito de interesses: inexistente

Suporte financeiro: não houve 